\title{
Physical parameters of insulation with a structure-forming material from flax noils
}

\author{
Sergey Romanovskiy ${ }^{1 *}$, Aleksandr Bakatovich ${ }^{1}$ \\ ${ }^{1}$ Polotsk State University, 211440, Blokhina 29, Novopolotsk, Belarus
}

\begin{abstract}
The results of studies to evaluate the effective operation of the obtained thermal insulation slabs made of flax fibers or noils were carried out. The sorption moisture content of insulants based on flax fibers or noils with modified liquid glass was determined at a relative humidity of 40 $97 \%$. The influence of humidity on the thermal conductivity of the test materials was studied. The coefficient of vapor permeability of insulation made of flax fibers or noils was established. The results of field tests of experimental thermal insulation materials on the attic flooring of a residential building during the cold season were considered. The graphs of the temperature distribution over the structure of the attic flooring and heat flow indicators were obtained. The values of the heat transfer resistance of the attic flooring were calculated at an air temperature of $-20{ }^{\circ} \mathrm{C}$ to $-2{ }^{\circ} \mathrm{C}$. The moisture content of insulation at the end of the cold period was determined and the dependence of the distribution of moisture over the thickness of the thermal insulation layer was plotted. The results of the tests carried out indicate the highest efficiency of thermal insulation slabs made of flax fiber noils in comparison with insulants based on flax fibers.

Key words: flax fiber, flax noils, physical parameters.
\end{abstract}

\section{Introduction}

Plant waste is a continually renewable, large-tonnage product produced all over the world. Technologies for the use of plant raw materials are being implemented in many countries for the production of fibrous thermal insulation materials. This is due to the high physical and mechanical properties and environmental cleanliness of the resulting insulation. The research results, as well as the characteristics of the produced thermal insulation materials, confirm that plant-based compositions compete with traditional insulation materials, including mineral wool and expanded polystyrene.

In countries with large timber reserves, including Russia, research is being conducted to develop insulants based on wood fibers and various binders, such as bio-based adhesive [1], polyvinyl acetate glue [2], paraffin emulsion [3], as well as without binder with the use of antiseptic and fire retardant [4]. At a density of $30-250 \mathrm{~kg} / \mathrm{m}^{3}$, thermal insulation materials have a thermal conductivity of $0.041 \mathrm{~W} /(\mathrm{m} \cdot \mathrm{K})$ to $0.06 \mathrm{~W} /(\mathrm{m} \cdot \mathrm{K})$.

\footnotetext{
* Corresponding author: s.romanovskiy@psu.by
} 
Compositions of insulation slabs based on recycled fiber mass from containerboard or fibrillated waste paper have been developed in Krasnoyarsk [5, 6]. Thermal conductivity of the materials ranges from $0.038-0.051 \mathrm{~W} /(\mathrm{m} \cdot \mathrm{K})$ with a density of 30 to $70 \mathrm{~kg} / \mathrm{m}^{3}$.

The most famous solution for the use of recycled waste paper for the production of insulation is ecowool, which consists of $80 \%$ of fibrous filler and $20 \%$ of fire retardants $[7 ; 8]$. The thermal insulation material has a density of $30-75 \mathrm{~kg} / \mathrm{m}^{3}$, providing a thermal conductivity of $0.032-0.041 \mathrm{~W} /(\mathrm{m} \cdot \mathrm{K})$ and a vapor permeability of $0.3 \mathrm{mg} /(\mathrm{m} \cdot \mathrm{h} \cdot \mathrm{Pa})$.

The possibility of using eucalyptus fibers as a filler for insulation was investigated in Chile [9]. The binder was phenolic resin. Thermal insulation material with an average density of $80 \mathrm{~kg} / \mathrm{m}^{3}$ to $250 \mathrm{~kg} / \mathrm{m}^{3}$ provides a thermal conductivity of $0.05-0.07$ $\mathrm{W} /(\mathrm{m} \cdot \mathrm{K})$.

An innovative development is an insulant based on sphagnum moss and liquid glass [10]. The thermal conductivity of the material is $0.034-0.04 \mathrm{~W} /(\mathrm{m} \cdot \mathrm{K})$ at a density of $155-$ $170 \mathrm{~kg} / \mathrm{m}^{3}$. However, thermal insulation slabs have a drawback, which is the material shrinkage during the drying process. To eliminate this problem, it was proposed to add crushed straw in an amount of $20-30 \%$ of the moss mass [11]. The new thermal insulating material has a thermal conductivity of $0.044-0.046 \mathrm{~W} /(\mathrm{m} \cdot \mathrm{K})$ and provides a compressive strength of 0.2-0.21 MPa with an average density of $156-190 \mathrm{~kg} / \mathrm{m}^{3}$.

Fibrous aggregates of agricultural origin are a significant reserve in the production of local thermal insulation building materials. For example, hemp-based slabs "Thermo-Hanf" are produced in Germany [12;13]. Insulation includes the following components: $83-87 \%$ of fibrous filler, $10-12 \%$ of polyester, and $3-5 \%$ of soda, used as a fire retardant. With an average density of $35-40 \mathrm{~kg} / \mathrm{m}^{3}$, the thermal insulation material has a thermal conductivity coefficient of $0.038-0.04 \mathrm{~W} /(\mathrm{m} \cdot \mathrm{K})$.

Insulation made from cotton waste and sodium water glass is of considerable interest for the countries of Central Asia. When varying density in the range of $40-100 \mathrm{~kg} / \mathrm{m}^{3}$, the thermal conductivity of the slabs changes from 0.037 to $0.041 \mathrm{~W} /(\mathrm{m} \cdot \mathrm{K})$ [14]. Under conditions of a relative humidity of $60-70 \%$, the moisture content of the insulating material is $11-12 \%$ [15].

Petronas University of Technology (Malaysia) studied the possibility of using oil palm bark fibers as a structure-forming insulation material [16]. According to the test results, it was found that when the density varies from $66 \mathrm{~kg} / \mathrm{m}^{3}$ to $110 \mathrm{~kg} / \mathrm{m}^{3}$, the thermal conductivity coefficient of the material changes in the range of $0.03-0.09$ $\mathrm{W} /(\mathrm{m} \cdot \mathrm{K})$.

Research on the production of thermal insulation slabs made of oil palm bark fibers up to $4 \mathrm{~cm}$ long and sodium water glass were carried out at Polotsk State University [17]. Lime and gypsum additives were used to increase the water resistance of the binder. The insulation has a density of $135-168 \mathrm{~kg} / \mathrm{m}^{3}$, providing thermal conductivity of $0.046-0.047 \mathrm{~W} /(\mathrm{m} \cdot \mathrm{K})$ and compressive strength of $0.2-0.24$ $\mathrm{MPa}$ at $10 \%$ linear deformation. High resistance of fibers to decay is noted at a relative humidity of $97 \%$.

Ecological insulation from flax fibers "Ecoteplin" is produced in Russia. Flax fibers are the filler in thermal insulation slabs. Starch is used as a binder. Boron salts are added to increase fire protection and prevent the formation of mold and fungi [18]. The material has the following characteristics: average density of $32-34 \mathrm{~kg} / \mathrm{m}^{3}$, thermal conductivity of $0.038-0.04 \mathrm{~W} /(\mathrm{m} \cdot \mathrm{K})$, sound absorption coefficient of $0.74-0.98$, vapor permeability of $0.403 \mathrm{mg} /(\mathrm{m} \cdot \mathrm{h} \cdot \mathrm{Pa})$, flammability class G1 (slightly combustible) [19].

In Belarus, thermal insulation slabs of the "Akoterm Flax" trademark are produced [19]. The insulation contains $85 \%$ of flax fibers and $15 \%$ of polyester fibers. The thermal conductivity of the material corresponds to $0.038-0.04 \mathrm{~W} /(\mathrm{m} \cdot \mathrm{K})$, 
vapor permeability is $0.4 \mathrm{mg} /(\mathrm{m} \cdot \mathrm{h} \cdot \mathrm{Pa})$, sound absorption is 0.98 with an average density of $30 \mathrm{~kg} / \mathrm{m}^{3}$.

The physical and mechanical characteristics of the described thermal insulation materials are shown in Table 1.

Table 1. Physical and mechanical characteristics of the thermal insulation materials

\begin{tabular}{|c|c|c|c|c|c|}
\hline № & Fillers & Binders & Additives & $\begin{array}{l}\text { Density, } \\
\mathrm{kg} / \mathrm{m}^{3}\end{array}$ & $\begin{array}{c}\text { Thermal } \\
\text { ductivity, } \mathrm{W} /(\mathrm{m}\end{array}$ \\
\hline 1 & wood fibers & bio-based adhesive & - & $50-100$ & - \\
\hline 2 & wood fibers & polyvinyl acetate glue & foaming agent & 81 & $0,042-0,05$ \\
\hline 3 & wood fibers & paraffin emulsion & - & $150-250$ & 0,06 \\
\hline 4 & wood fibers & - & $\begin{array}{l}\text { antiseptic and fire } \\
\text { retardant }\end{array}$ & $35-40$ & 0,041 \\
\hline 5 & recycled fiber mass & polyvinyl acetate glue & - & 69 & $0,049-0,051$ \\
\hline 6 & recycled fiber mass & - & boric acid and borax & $30-50$ & $0,038-0,041$ \\
\hline 7 & recycled waste paper & - & fire retardant & $30-75$ & $0,032-0,041$ \\
\hline 8 & eucalyptus fibers & phenolic resin & - & $80-250$ & $0,05-0,07$ \\
\hline 9 & sphagnum moss & liquid glass & - & $155-170$ & $0,034-0,04$ \\
\hline 10 & $\begin{array}{l}\text { sphagnum moss } \\
\text { and crushed straw }\end{array}$ & liquid glass & - & $156-190$ & $0,044-0,046$ \\
\hline 11 & hemp & polyester & soda & $35-40$ & $0,038-0,04$ \\
\hline 12 & cotton waste & liquid glass & - & $40-100$ & $0,037-0,041$ \\
\hline 13 & oil palm bark fibers & - & - & $66-110$ & $0,03-0,09$ \\
\hline 14 & oil palm bark fibers & liquid glass & lime and gypsum & $135-168$ & $0,046-0,047$ \\
\hline 15 & flax fibers & starch & boron salts & $32-34$ & $0,038-0,04$ \\
\hline 16 & flax fibers & polyester fibers & - & 30 & $0,038-0,04$ \\
\hline
\end{tabular}

The purpose of the complex studies carried out is to determine the physical parameters of thermal insulation slabs with a structure-forming flax noils material. For comparison, the physical and mechanical characteristics of insulants based on flax fibers are investigated. The use of flax noils for the slabs manufacture solves the problem of utilizing plant waste and expands the range of effective heat-insulation materials that are safe for the environment and human health.

\section{Method}

Samples of thermal insulation slabs were made from flax fibers up to $25 \mathrm{~cm}$ long or flax noils 5 to $10 \mathrm{~cm}$ long, obtained at a flax factory in Postavy (Belarus). Flax fiber consists of bundles of elementary fibers interconnected. The bundle diameter is 50-70 $\mu \mathrm{m}$. Each bundle contains from 10 to 20 connected along the length and tightly adjacent filaments. The length of an elementary fiber varies from 10 to $40 \mathrm{~mm}$, with a diameter of $8-12 \mu \mathrm{m}$. Flax fiber noils are loose bundles of elementary fibers. The structure of the bundle in the noils is formed from disheveled elementary fibers with chaotically located contact connections. As a binder in the production of thermal insulation materials, sodium liquid glass was used, produced at JSC "Domanovsky Production and Trade Plant". To ensure the insolubility of liquid glass, hydrated lime and gypsum were used as modifying additives.

The main physical and mechanical indicators of the materials under study, namely the average density and compressive strength at $10 \%$ linear deformation, were determined in accordance with GOST 17177 [20].

The thermal conductivity coefficient of insulants was measured with an ITP-MG4 "250" device in accordance with the requirements of STB 1618 [21]. 
The values of the sorption moisture content of thermal insulation materials were determined according to STB EN 12088 [22].

The study of the moisture index influence on the coefficient of thermal conductivity of samples of thermal insulation materials was carried out according to the method described in [23]. For the experiment, samples of insulation were made from flax noils and fibers with modified liquid glass in the form of slabs with dimensions of $250 \times 250 \times 50 \mathrm{~mm}$. Additionally, for comparative analysis, we used samples of thermal insulation slabs "Akoterm Flax" based on a mixture of flax and polyester fibers. After determining the density and thermal conductivity of the slabs in a dry state, each sample was placed in an individual sealed chamber with pre-filled water below the material installation level by 40 $\mathrm{mm}$. The air temperature in the chamber corresponded to $20 \pm 2{ }^{\circ} \mathrm{C}$, and the relative air humidity was $97 \%$. The test conditions reflect the most unfavorable humidity conditions for thermal insulation slabs - the period during and after rainfall. The thermal insulation slabs were kept in a chamber above water for 2, 5, 10 and 20 days, after which they were removed and the thermal conductivity coefficient was determined. Complete stabilization of the moisture index occurred after 20 days, which determines the maximum period of keeping the samples in a sealed chamber. The frequency of indicators determination is due to the most characteristic changes in the dynamics of humidity and thermal conductivity of the samples.

The vapor permeability of thermal insulation materials was determined in accordance with STB EN 12086 [24].

The thermophysical properties of thermal insulation slabs under operating conditions were determined using the data measurement complex RTP-1-16T. The values of changes in the ambient air temperatures and the materials under study were recorded with thermocouples, and the values of the heat flux were determined using heat flux converters. Samples from flax noils or fibers were made in the form of slabs with dimensions $1000 \times 600 \times 100 \mathrm{~mm}$. Insulation materials were placed between the wooden beams of the attic flooring of a one-storey residential building (Fig. 1). Inter-girder construction of the attic flooring included an edged ceiling covering board, a vapor barrier layer, thermal insulation slabs based on flax fibers (flooring 1), flax noils (flooring 2) and a mixture of flax and polyester fibers (flooring 3), as well as a hydro- and windproof membrane. The cross-sectional diagram of the attic flooring is shown in Figure 2.

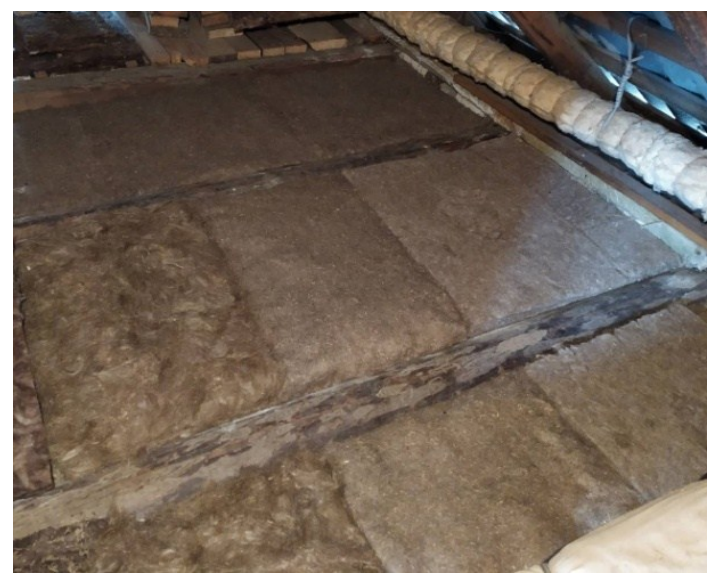

Fig. 1. Thermal insulation slabs made of flax fibers, flax noils,mixture of flax and polyester fibers (from left to right) on the attic flooring 
The moisture content of the insulants after testing under operating conditions was determined in accordance with GOST 17177 . Prism samples $50 \times 50 \times 300 \mathrm{~mm}$ in size were preliminarily cut through the thickness of the thermal insulation materials. The prism sample was cut in the transverse direction into individual fragments $50 \mathrm{~mm}$ long, obtaining samples in the form of cubes. Then each cube sample was weighed and placed in an drying cabinet. Upon reaching a constant mass, the sample cubes were weighed again. The moisture content was determined by the amount of change in the sample cubes mass before and after drying. The sampling scheme is shown in Figure 3.

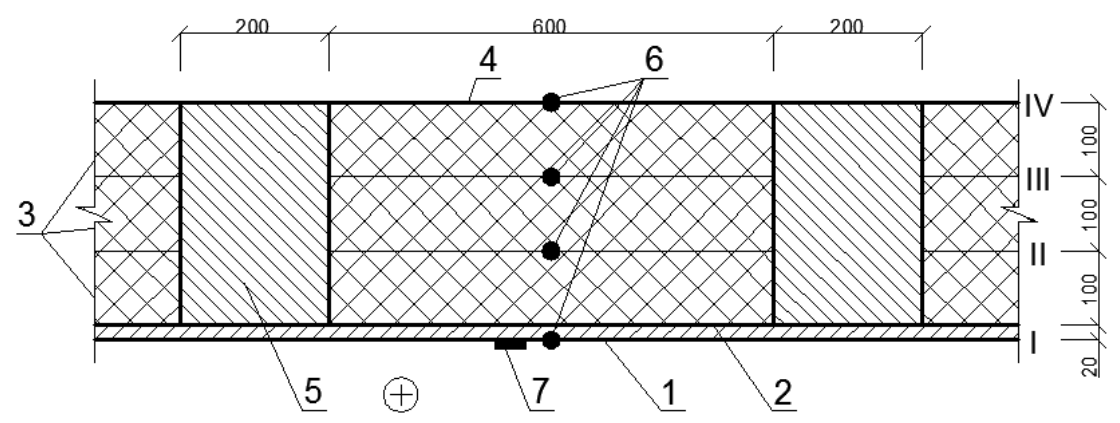

1 - edged ceiling covering board; 2 - vapor barrier layer; 3 - thermal insulation slabs; 4 - hydro- and windproof membrane; 5 - wooden beam of the flooring; 6 - thermocouples; 7 - heat flux converter; I, II, III, IV - thermocouple installation site boundaries

Fig. 2. Cross-sectional diagram of the attic flooring

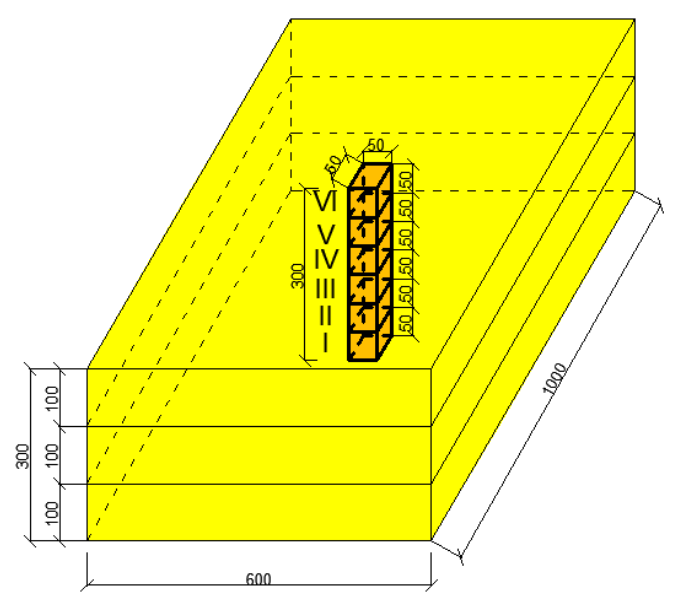

I-VI - sample numbers

Fig. 3. Sampling scheme from thermal insulation boards

\section{Results and discussion.}

To determine the quantitative composition of the experimental samples, structure-forming material consumption was changed at a constant consumption of a binder equal to $10 \mathrm{~kg}$ 
and consisting of liquid sodium glass $-9 \mathrm{~kg}$, lime $-0.5 \mathrm{~kg}$, and gypsum - $0.5 \mathrm{~kg}$. The accepted consumption of the binder had a minimal effect on the thermal conductivity coefficient, while providing a coherent structure of the insulation. Research and results on the selection of binder consumption are discussed in a previously published work. The physical and mechanical characteristics of the samples obtained are shown in Table 2.

According to the research results, it has been found that an increase in the consumption of the structure-forming material leads to an increase in the density of the insulation up to $70 \mathrm{~kg} / \mathrm{m}^{3}$ (compositions 5 and 6) and, regardless of the type of fibers, provides a decrease in the thermal conductivity coefficient. A further increase in the density of samples (compositions 9 and 10) causes an increase in the thermal conductivity of insulants. At a density of $50 \mathrm{~kg} / \mathrm{m}^{3}$ for slabs based on flax (composition 2), the thermal conductivity is $0.041 \mathrm{~W} /(\mathrm{m} \cdot \mathrm{K})$. A decrease in the thermal conductivity coefficient by $15 \%$ occurs with an increase in density by 1.4 times to $70 \mathrm{~kg} / \mathrm{m}^{3}$ (composition 6). With an increase in the average density to $90 \mathrm{~kg} / \mathrm{m}^{3}$ (composition 10 ), an increase in thermal conductivity up to $0.037 \mathrm{~W} /(\mathrm{m} \cdot \mathrm{K})$ is noted. For slabs made of flax fibers, a similar dependence has been established, so the minimum value of the thermal conductivity coefficient of 0.042 $\mathrm{W} /\left(\mathrm{m} \cdot \mathrm{K}\right.$ ) corresponds to a density of $70 \mathrm{~kg} / \mathrm{m}^{3}$ (composition 5 ). A decrease in density to 50 $\mathrm{kg} / \mathrm{m}^{3}$ (composition 1) and an increase to $90 \mathrm{~kg} / \mathrm{m}^{3}$ (composition 9) leads to an increase in the thermal conductivity coefficient by $14 \%$ and $7 \% \mathrm{~W} /(\mathrm{m} \cdot \mathrm{K})$, respectively.

Table 2. Physical and mechanical characteristics of the samples

\begin{tabular}{|c|c|c|c|c|c|}
\hline \multirow{2}{*}{$\begin{array}{c}\text { Composition } \\
\text { No. }\end{array}$} & \multicolumn{2}{|c|}{$\begin{array}{c}\text { Consumption of } \\
\text { structure-forming } \\
\text { material per 1 } \mathrm{m}^{3}, \\
\mathrm{~kg}\end{array}$} & $\begin{array}{c}\text { Density, } \\
\mathrm{kg} / \mathrm{m}^{3}\end{array}$ & $\begin{array}{c}\text { Coefficient of thermal } \\
\text { conductivity, } \mathrm{W} /(\mathrm{m} \cdot \mathrm{K})\end{array}$ & $\begin{array}{c}\text { Compressive } \\
\text { strength at } 10 \% \\
\text { deformation, } \mathrm{kPa}\end{array}$ \\
\cline { 2 - 4 } & flax fiber & flax noils & & 0,048 & 1,8 \\
\hline 1 & 40 & - & 50 & 0,041 & 1,1 \\
\hline 2 & - & 40 & 50 & 0,045 & 2,4 \\
\hline 3 & 50 & - & 60 & 0,039 & 1,7 \\
\hline 4 & - & 50 & 60 & 0,042 & 3 \\
\hline 5 & 60 & - & 70 & 0,035 & 2,1 \\
\hline 6 & - & 60 & 70 & 0,042 & 3,4 \\
\hline 7 & 70 & - & 80 & 0,035 & 2,4 \\
\hline 8 & - & 70 & 80 & 0,045 & 3,7 \\
\hline 9 & 80 & - & 90 & 0,037 & 2,6 \\
\hline 10 & - & 80 & 90 & & \\
\hline
\end{tabular}

The analysis of the results presented in Table 2 shows that an increase in the density of thermal insulation slabs at a constant binder consumption provides an increase in the compressive strength at $10 \%$ deformation. Thus, the compressive strength of flax noils insulants (composition 2) is $1.1 \mathrm{kPa}$ at a density of $50 \mathrm{~kg} / \mathrm{m}^{3}$. An increase in the average density by 1.8 times (composition 10) leads to an increase in strength by 2.4 times to $2.6 \mathrm{kPa}$. Samples of materials based on flax fibers at a maximum density of $90 \mathrm{~kg} / \mathrm{m}^{3}$ (composition 9) reach a strength of $3.7 \mathrm{kPa}$. A decrease in density to $50 \mathrm{~kg} / \mathrm{m}^{3}$ (composition 1) causes a 2-fold decrease in the compressive strength at $10 \%$ deformation. It should be noted that in the investigated range of densities, the compressive strength is higher for thermal insulation materials made of flax fibers by an average of $33 \%$ compared to slabs based on flax fiber noils. 
Due to the low strength characteristics of insulants based on flax fibers and noils, when choosing the compositions of thermal insulation slabs for further research, the minimum thermal conductivity coefficient was taken as the determining indicator. Thus, further studies of insulants were carried out on samples with an average density of $70 \mathrm{~kg} / \mathrm{m}^{3}$, which provide the best thermal conductivity. Additionally, samples of "Akoterm Flax" slabs with a thermal conductivity coefficient of $\quad 0.04 \mathrm{~W} /(\mathrm{m} \cdot \mathrm{K})$ at a density of $34 \mathrm{~kg} / \mathrm{m}^{3}$ were used in the studies. Insulation molding technology does not allow the production of higher density material. The quantitative composition, average density and thermal conductivity of the dry samples for further research are shown in Table 3.

Table 3. Compositions, average density and thermal conductivity of samples

\begin{tabular}{|c|c|c|c|c|c|c|c|c|}
\hline \multirow{2}{*}{$\begin{array}{c}\text { Composition } \\
\text { No. }\end{array}$} & $\begin{array}{c}\text { flax } \\
\text { fiber }\end{array}$ & $\begin{array}{c}\text { flax } \\
\text { noils }\end{array}$ & $\begin{array}{c}\text { liquid } \\
\text { glass }\end{array}$ & $\begin{array}{c}\text { polyester } \\
\text { fiber }\end{array}$ & lime & gypsum & $\begin{array}{c}\text { Average } \\
\text { density, } \\
\mathrm{kg} / \mathrm{m}^{3}\end{array}$ & $\begin{array}{c}\text { Coefficient of } \\
\text { thermal } \\
\text { conductivity, } \\
\mathrm{W} /(\mathrm{m} \cdot \mathrm{K})\end{array}$ \\
\hline 1 & 60 & - & 9 & - & 0,5 & 0,5 & 70 & 0,042 \\
\hline 2 & - & 60 & 9 & - & 0,5 & 0,5 & 70 & 0,035 \\
\hline 3 & 29 & - & - & 5 & - & - & 34 & 0,04 \\
\hline
\end{tabular}

\section{Sorption moisture.}

To study the sorption moisture content of thermal insulation materials based on plant fibers, the compositions given in Table 3 were taken. Experimental data were used to plot the dependences of the material sorption moisture content on the relative air humidity in the form of sorption isotherms (Fig. 4).

From the analysis of the obtained dependences (Fig. 4), it follows that at an air humidity of $40 \%$, the sorption humidity of the thermal insulation material from the noils is $10.2 \%$, which is $10 \%$ lower than the values of the samples based on flax fibers and higher than the indicator of the "Akoterm Flax" insulation material by 59\%. The sorption humidity of composition 1 at a relative air humidity of $60 \%$ is $15.4 \%$. For composition 2 , the sorption moisture is less than the material index (composition 1) by $9 \%$, and more samples (composition 3 ) by $24 \%$. An increase in the sorption moisture content of samples from flax noils to $18.3 \%$ occurs at an air humidity of $80 \%$, which practically coincides with the value of samples based on flax fibers and exceeds the indicator of a material made from a mixture of flax and polyester fibers by $17 \%$. The values of the sorption moisture content of the samples (compositions 1,3) are less by $9 \%$ and $15 \%$ in comparison with the samples based on flax noils, equal to $26.8 \%$ at a relative air humidity of $90 \%$. At an air humidity of $97 \%$ in a desiccator, the sorption of the material from flax noils increases to $37.6 \%$, which is $13 \%$ and $19 \%$ more than for samples based on flax fibers and "Akoterm Flax" thermal insulation material. 


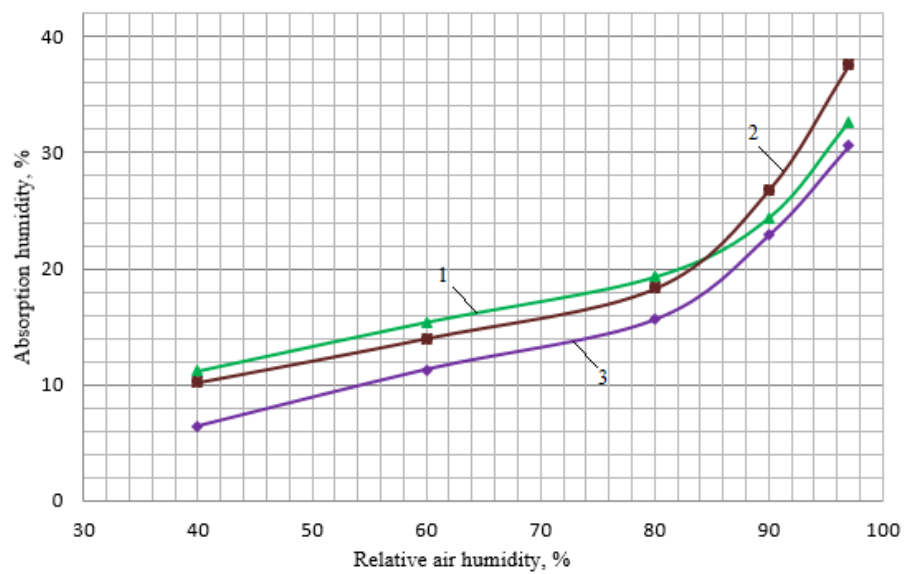

1 - samples with flax fibers; 2 - samples with flax noils; 3 - "Akoterm Flax" samples

Fig. 4. Isotherms of water vapor sorption

The excess of the sorption moisture content of the samples based on flax noils relative to the indicators of compositions 1 and 3 at a relative air humidity of $90-97 \%$ is due to the significant value of the sorption moisture content of flax noils in comparison with flax and polyester fibers. Separated elementary fibers in noils have a large geometrical area of surface contact with the external environment relative to the indicators of flax fiber, consisting of dense bundles of elementary fibers. The presence of polyester fibers in "Akoterm Flax" slabs leads to an additional decrease in the moisture absorbed by the material from the air and, accordingly, reduces the rate of water vapor sorption by insulation samples.

\section{Influence of humidity on the coefficient of thermal conductivity}

The quantitative composition, average density and thermal conductivity of the samples for the study are shown in Table 3. The dry weight of the samples from flax noils or fibers is 219 g, and "Akoterm Flax" samples are 106 g. The laboratory test results are shown in Table 4.

Table 4. Indicators of mass, moisture and thermal conductivity of wet samples

\begin{tabular}{|c|c|c|c|c|}
\hline \multirow[b]{2}{*}{$\begin{array}{c}\text { Composition } \\
\text { No. }\end{array}$} & \multirow{2}{*}{$\begin{array}{l}\text { Holding time of } \\
\text { samples in the } \\
\text { chamber, days } \\
\text { (hours) }\end{array}$} & \multicolumn{3}{|c|}{ Wet sample indicators } \\
\hline & & weight, $g$ & humidity, $\%$ & $\begin{array}{l}\text { thermal conductivity coefficient, } \\
\qquad \mathrm{W} /(\mathrm{m} \cdot \mathrm{K})\end{array}$ \\
\hline \multicolumn{5}{|c|}{ Flax fiber insulation } \\
\hline 1 & $2(48)$ & 238,9 & 9,1 & 0,049 \\
\hline 2 & $5(120)$ & 264,3 & 20,7 & 0,06 \\
\hline 3 & $10(240)$ & 278,6 & 27,2 & 0,072 \\
\hline 4 & $20(480)$ & 290,3 & 32,1 & 0,08 \\
\hline \multicolumn{5}{|c|}{ Flax noils insulation } \\
\hline 5 & $2(48)$ & 239,4 & 9,3 & 0,043 \\
\hline 6 & $5(120)$ & 269,8 & 23,2 & 0,058 \\
\hline 7 & $10(240)$ & 290 & 32,4 & 0,067 \\
\hline 8 & $20(480)$ & 299,4 & 36,9 & 0,075 \\
\hline
\end{tabular}




\begin{tabular}{|c|c|c|c|c|}
\hline 9 & $2(48)$ & 114,4 & 7,9 & 0,048 \\
\hline 10 & $5(120)$ & 124,9 & 17,8 & 0,063 \\
\hline 11 & $10(240)$ & 131,9 & 24,4 & 0,074 \\
\hline 12 & $20(480)$ & 137,8 & 30 & 0,081 \\
\hline
\end{tabular}

From the experimental data (table 4 ) it follows that in 48 hours the moisture index of samples 5 based on flax noils reaches $9.3 \%$ and is almost identical to the value of samples 1, while the moisture content of the "Akoterm Flax" insulation is $18 \%$ higher (samples 9). For samples 6 based on noils, after 5 days from the start of testing, the humidity increases to $23.2 \%$, which is $12 \%$ and $30 \%$ more than the values of slabs 2 and 10. During the next 5 days, a gradual increase in the moisture index for all materials occurs. The moisture value of slabs 7 based on flax strips after 10 days is $32.4 \%$, which exceeds the values of samples 3 and 11 by $19 \%$ and $33 \%$, respectively. Relative to the dry materials indicators, the moisture content of samples 8 has increased to $36.9 \%$ after 20 days of testing, and the increase in the moisture content of flax noils relative to samples 4 and 12 is $15 \%$ and $23 \%$.

The experimental data obtained indicate that after 48 hours of testing, the value of thermal conductivity of thermal insulation slabs (samples 5) based on flax noils increased by $23 \%$. Over the same period of time, the thermal conductivity of flax fibers samples 1 and 9 increased by $20 \%$. After 5 days of keeping the slabs in a sealed chamber, the thermal conductivity of samples 6,2 , and 9 based on noils and flax fibers increased by $46 \%, 66 \%$, and $58 \%$, respectively. The change in thermal conductivity for the second 120 hours is $16 \%$ for samples 7 from flax fiber noils, which is $61 \%$ less than the change in the index of the same material for the first 120 hours. For slabs 3 and 10 based on flax fibers, the change in the value of thermal conductivity over the same period of time is $20 \%$ and $17 \%$, respectively. The thermal conductivity of samples 4,8 and 12 after 20 days of testing increases by 2-2.1 times relative to the indicators of dry materials.

Lower coefficients of thermal conductivity of flax fiber noils samples are achieved due to the multidirectional arrangement of elementary fibers in the structure of the insulation. This prevents convective air transport as a result of a decrease in the size of thin air layers of irregular shape and their partial localization in the form of separate closed microvoids. Thus, in spite of the higher moisture content of the noils slabs, the obtained structure of elementary fibers allows to provide identical thermal conductivity values with flax fiber slabs and "Akoterm Flax" insulation.

\section{Water vapor permeability}

For testing, samples of thermal insulation slabs based on flax noils and fibers with dimensions $110 \times 110 \times 50 \mathrm{~mm}$ were made. The composition, density and vapor permeability of the samples under study are presented in Table 5.

Table 5. Composition, density and vapor permeability of samples

\begin{tabular}{|c|c|c|c|c|c|}
\hline \multirow{2}{*}{$\begin{array}{c}\text { Composition } \\
\text { No. }\end{array}$} & \multicolumn{3}{|c|}{ Component consumption per $1 \mathrm{~m}^{3}, \mathrm{~kg}$} & \multirow{2}{*}{ Density, $\mathrm{kg} / \mathrm{m}^{3}$} & \multirow{2}{*}{$\begin{array}{l}\text { Water vapor } \\
\text { permeability, } \\
\mathrm{mg} /(\mathrm{m} \cdot \mathrm{h} \cdot \mathrm{Pa})\end{array}$} \\
\hline & flax fiber & flax noils & binder & & \\
\hline 1 & 30 & - & 10 & 40 & 0,43 \\
\hline 2 & - & 30 & 10 & 40 & 0,41 \\
\hline 3 & 70 & - & 10 & 80 & 0,41 \\
\hline 4 & - & 70 & 10 & 80 & 0,37 \\
\hline
\end{tabular}




\begin{tabular}{|l|c|c|c|c|c|}
\hline 5 & 110 & - & 10 & 120 & 0,38 \\
\hline 6 & - & 110 & 10 & 120 & 0,34 \\
\hline
\end{tabular}

According to the research results (Table 5), it has been found that with a minimum average density of $40 \mathrm{~kg} / \mathrm{m}^{3}$, the vapor permeability index of samples of flax fiber noils is practically identical to that of flax fiber insulation. For samples based on flax noils or fibers with an average density of $80 \mathrm{~kg} / \mathrm{m}^{3}$, a decrease in vapor permeability is observed relative to the indicators of samples 1 and 2 . The vapor permeability coefficient for slabs made of flax noils is $10 \%$ less than that for materials based on flax fibers at the same density value. With an increase in the average density of samples to $120 \mathrm{~kg} / \mathrm{m}^{3}$, the vapor permeability coefficient of thermal insulation slabs made of flax fibers is $12 \%$ higher than that of samples made of flax noils.

Thus, with an increase in the average density of thermal insulation materials, the vapor permeability index decreases. The investigated parameter of the noils insulation at a density of $40 \mathrm{~kg} / \mathrm{m}^{3}$ decreases by $17 \%$ with an increase in the average density to $120 \mathrm{~kg} / \mathrm{m}^{3}$. For samples based on flax fibers with a minimum density of $40 \mathrm{~kg} / \mathrm{m}^{3}$, the vapor permeability is $12 \%$ higher than that at a maximum density of $120 \mathrm{~kg} / \mathrm{m}^{3}$.

\section{Thermal performance of insulants under operating conditions}

During the autumn and spring period 2018-2019, observations were made of the thermophysical processes occurring in the construction of the attic flooring of an operated one-story residential building with the use of experimental thermal insulation materials. As an example, the period from January 20 to January 29, 2019, equal to 10 days, with the lowest night outdoor temperatures in the Polotsk district of the Vitebsk region (Belarus), is considered. The compositions of the investigated thermal insulation slabs are shown in Table 3. According to the results of measurements, it has been found that the temperature distribution for thermal insulation slabs made of a mixture of flax and polyester fibers ("Akoterm Flax" insulation) is identical with insulation made of flax fiber noils. Figure 5 shows the distribution of the outside air temperatures in the attic and the space between the beams of the attic flooring (including insulation) at night. Temperature values are taken as average values of temperature readings from 22:00 to 6:00.

a

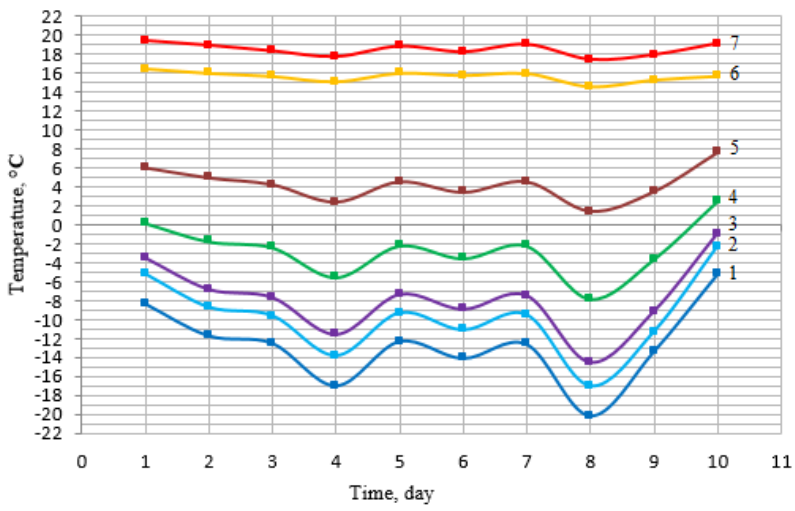




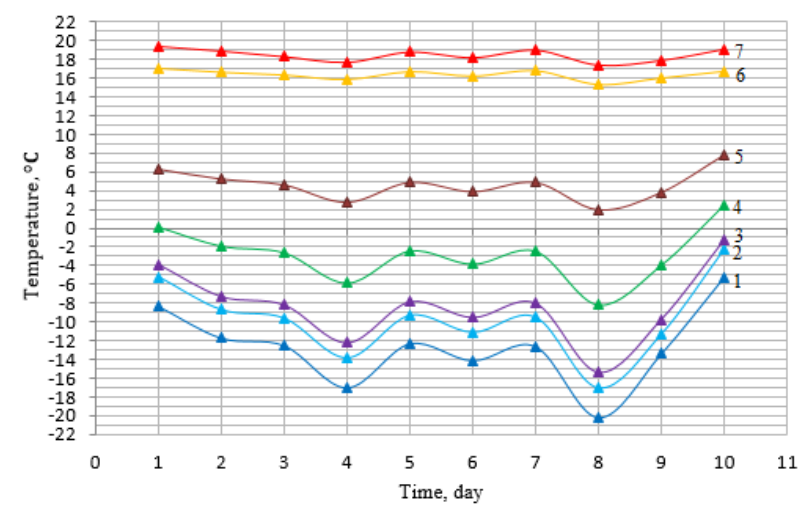

$\mathrm{a}$ - flax fiber insulation; $\mathrm{b}$-flax noils insulation

1 - outside air temperature; 2 - temperature in the attic, ${ }^{\circ} \mathrm{C} ; 3$ - temperature of 3 layers at border-line IV temperature of 3 layers at border-line III; 5 - temperature of 3 layers at border-line II; 6 - temperature of layer at border-line I; 7 - air temperature in the dwelling, ${ }^{\circ} \mathrm{C}$

Fig. 5. Temperature distribution over the thickness of the attic flooring for a period of 10 days

From the temperature distribution graphs (Fig. 5) it has been found that the coldest hours are the night hours of the eighth day. At night on the eighth day, the temperature amplitude on the surfaces of the attic flooring with thermal insulation slabs made of noils is $30.7^{\circ} \mathrm{C}$, which is identical with the attic flooring 3 and practically coincides with the values of flooring 1 , equal to $29.1^{\circ} \mathrm{C}$.

Based on the temperature distribution graphs in table 6 , the average values of the temperature distribution in the living room, attic flooring, as well as outside air and attic temperatures for the time period under consideration are given.

Table 6. Average temperatures

\begin{tabular}{|l|c|c|c|}
\hline \multicolumn{1}{|c|}{ Indicator } & Flooring 1 & Flooring 2 & Flooring 3 \\
\hline Outside air temperature, ${ }^{\circ} \mathrm{C}$ & $-12,7$ & $-12,7$ & $-12,7$ \\
\hline Attic air temperature, ${ }^{\circ} \mathrm{C}$ & $-9,8$ & $-9,8$ & $-9,8$ \\
\hline $\begin{array}{l}\text { Temperature of the third layer at border- } \\
\text { line IV, }{ }^{\circ} \mathrm{C}\end{array}$ & $-7,8$ & $-8,6$ & $-8,5$ \\
\hline $\begin{array}{l}\text { Temperature of the third layer at border- } \\
\text { line III, }{ }^{\circ} \mathrm{C}\end{array}$ & $-1,8$ & $-2,8$ & $-2,6$ \\
\hline $\begin{array}{l}\text { Temperature of the third layer at border- } \\
\text { line II, }{ }^{\circ} \mathrm{C}\end{array}$ & 3,7 & 4,6 & 4,2 \\
\hline Temperature of 1 layer at border-line I, ${ }^{\circ} \mathrm{C}$ & 15,6 & 16,4 & 16,4 \\
\hline Indoor air temperature, ${ }^{\circ} \mathrm{C}$ & 18,5 & 18,5 & 18,5 \\
\hline
\end{tabular}

From the data presented in Table 6, it follows that for the attic flooring with flax noils insulation, the average temperature of the inner surface at the border-line I for 10 days is $0.8{ }^{\circ} \mathrm{C}$ higher than for the flooring with thermal insulation material based on flax fibers and is identical to the attic flooring with "Akoterm Flax" slabs. When comparing the average temperatures for 10 days at border-line II, it has been found that for the flooring with thermal insulation slabs made of flax fiber noils, the average temperature value is $0.9^{\circ} \mathrm{C}$ higher than for the attic flooring with insulation based on flax fibers and practically coincides with the flooring 3 indicator. For a similar period of time, the average temperature at the border-line III of flooring 2 is $1{ }^{\circ} \mathrm{C}$ less than that of attic flooring 1 and is identical to the value of flooring 3 . At border-line IV for 10 days, the average temperature of the outer surface of the attic flooring with the material based on noils does not differ from indicators of flooring with insulation (composition 3, table. 3 ) and 0.8 ${ }^{\circ} \mathrm{C}$ lower than that of flooring with slabs of flax fibers. 
Based on the obtained values of heat flux densities, the thermal resistances of the attic flooring structures with experimental insulants were determined. Figure 6 shows the dependence of thermal resistance on air temperature in an unheated attic.

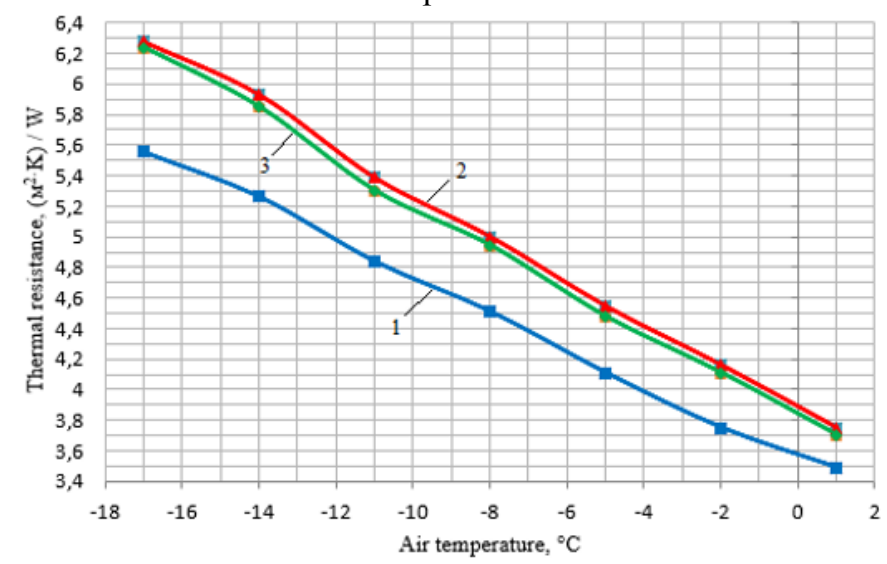

1 - flax fiber insulation; 2 - flax noils insulation; 3 - insulation made from a mixture of polyester and flax fibers

Fig. 6. Dependence of the thermal resistance of the attic flooring structure on the air temperature in an unheated attic

From the dependences shown in Fig. 6 it follows that the thermal resistance value of the attic flooring with flax fiber noils insulation is $3.53\left(\mathrm{~m}^{2} \cdot \mathrm{K}\right) / \mathrm{W}$ at an attic air temperature of $+1{ }^{\circ} \mathrm{C}$, which practically coincides with the value of the flooring with thermal insulation materials based on flax and polyester fibers and $0.27\left(\mathrm{~m}^{2} \cdot \mathrm{K}\right) / \mathrm{W}$ more than the flooring with flax fiber slabs. The thermal resistance value of flooring 2 at an air temperature in the attic of $-8{ }^{\circ} \mathrm{C}$ is $5\left(\mathrm{~m}^{2} \cdot \mathrm{K}\right) / \mathrm{W}$, which is $11 \%$ more than the thermal resistance of flooring 1 and does not differ from the flooring 3 indicator. At an air temperature in the attic of $-17{ }^{\circ} \mathrm{C}$ thermal resistance of an attic flooring with thermal insulation materials (composition 2) is identical to the value of an attic flooring with "Akoterm Flax" insulants and is 13\% higher than the value for an attic flooring with a flax fiber material equal to $5.56\left(\mathrm{~m}^{2} \cdot \mathrm{K}\right) / \mathrm{W}$.

In the spring, after the end of the monitoring, the values of the moisture content of thermal insulation materials were determined. The change in moisture content across the thickness of the insulation is shown in Figure 7.

On the basis of the obtained data on the distribution of moisture content over the thickness of thermal insulation slabs (Fig. 7), the average moisture content of the material from flax noils was established to be equal to $12.1 \%$. The obtained value for composition 2 is lower than the moisture index of the fiber-based slab (composition 1) by $14 \%$ and higher by $14 \%$ than the value of the insulation based on a mixture of flax and polyester fibers (composition 3). At the same time, in layer I, the moisture content of the thermal insulation material made of flax noils is $17 \%$ less than the moisture content of the insulation (composition 1), equal to $11.3 \%$ and 1.25 times more than that of "Akoterm Flax" slab. In layer VI, the moisture content of the material based on flax noils is $13.8 \%$, which is $13 \%$ less than the moisture content of the flax fiber insulation and $10 \%$ higher than that of the slab based on flax and polyester fibers.

According to the results of previous studies of the effective insulants operation on the attic flooring without a hydro-wind protection device, it has been found that the moisture content of insulants containing flax noils is $17.6 \%$, flax fibers $19.3 \%$, a mixture of flax and polyester fibers $14.1 \%$. The hydro-wind protection device reduces the moisture sorption of the insulation from the air of the attic space, which makes it possible to reduce the moisture content of the investigated thermal insulation materials by an average of $31 \%$ and increase the thermal resistance to $6.27\left(\mathrm{~m}^{2} \cdot \mathrm{K}\right) / \mathrm{W}$ with a thermal insulation layer thickness of $300 \mathrm{~mm}$. 


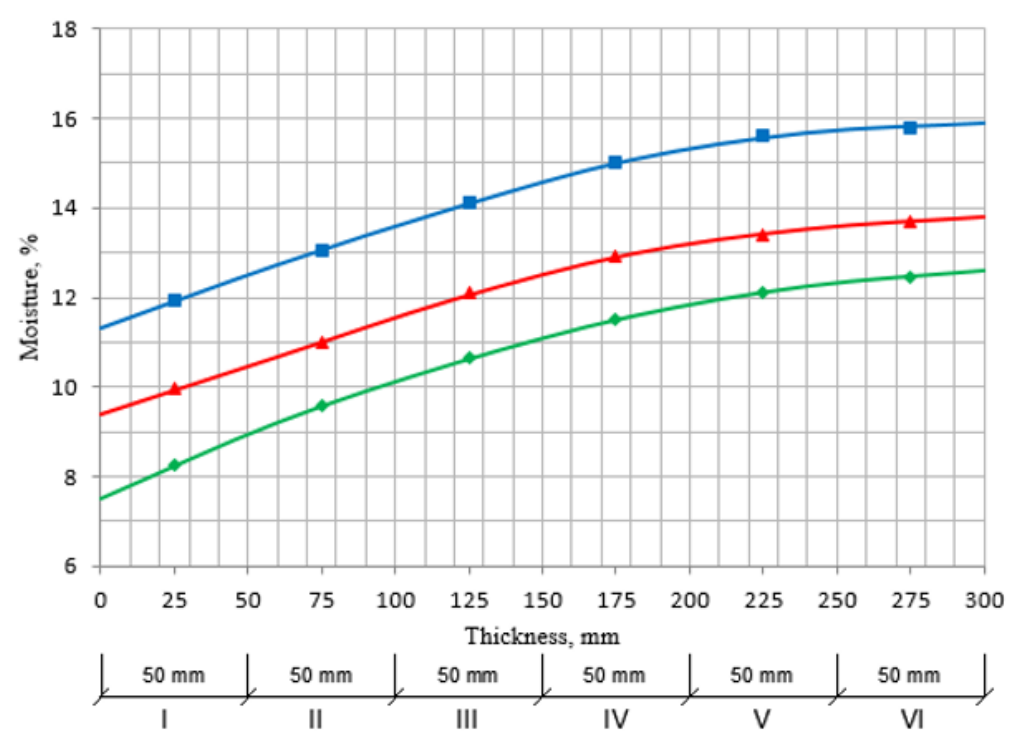

1 - flooring with flax fiber insulation; 2 - flooring with flax noils insulation;

3 - flooring with insulation made of a mixture of polyester and flax fibers

Fig. 7. Distribution of moisture in the thickness of the insulation

\section{Conclusions}

According to the research results, effective thermal insulation slabs from flax fiber noils with a density of $70 \mathrm{~kg} / \mathrm{m}^{3}$, characterized by a low thermal conductivity coefficient of 0.035 $\mathrm{W} /\left(\mathrm{m}^{2} \cdot \mathrm{K}\right)$, were obtained.

According to the results of tests of sorption humidity by the desiccator method, it was found that at a relative air humidity of $97 \%$, the indicators of the sorption humidity of samples based on flax fibers and noils are $32.7 \%$ and $37.6 \%$, which exceeds the value of "Akoterm Flax" slabs equal to $30.6 \%$ by $7 \%$ and $23 \%$, respectively. The obtained data on the kinetics of water vapor sorption by thermal insulation slabs will allow calculating the humidity regime of the structure. Also, the experimental data is supposed to be used in the future in the development of a predictive model of changes in the thermal characteristics of insulants during the operation of buildings and structures.

As a result of the conducted studies on the effect of moisture on the thermal conductivity of fiber-structure insulants, it has been determined that a change in the moisture index has a significant effect on the thermal conductivity coefficient of slabs based on noils, flax fibers, or mixture of flax and polyester fibers. An increase in the moisture content of thermal insulation materials made of flax noils provides an increase in thermal conductivity by a factor of 2.1 to $0.075 \mathrm{~W} /(\mathrm{m} \cdot \mathrm{K})$ relative to dry samples. For insulants made of flax fibers and "Akoterm Flax" slabs, moisture absorption leads to an increase in thermal conductivity to values of $0.08 \mathrm{~W} /(\mathrm{m} \cdot \mathrm{K})$ and $0.081 \mathrm{~W} /(\mathrm{m} \cdot \mathrm{K})$, respectively, which exceeds the indicators of dry materials by 2 times. Thus, with a moisture content that is $19 \%$ higher than the value of "Akoterm Flax" slabs equal to $30 \%$, thermal insulation material based on noils provides an identical coefficient of thermal conductivity in a wet state.

To perform calculations of the enclosing structures moisture regime, the vapor permeability of thermal insulation materials made of flax fibers and noils was determined. With an average density of $40-120 \mathrm{~kg} / \mathrm{m}^{3}$, the vapor permeability of noils-based insulants is 
$0.34-0.41 \mathrm{mg} /(\mathrm{m} \cdot \mathrm{h} \cdot \mathrm{Pa})$, and for flax fiber samples it ranges from $0.38 \mathrm{mg} /(\mathrm{m} \cdot \mathrm{h} \cdot \mathrm{Pa})$ to $0.43 \mathrm{mg} /(\mathrm{m} \cdot \mathrm{h} \cdot \mathrm{Pa})$.

The use of hydro-wind protection in the construction of the attic flooring allows to reduce the moisture content of thermal insulation materials during the operation of the building by an average of $31 \%$. This constructive solution reduces the moisture sorption by insulation from the air in the attic. As a result, in spite of the higher moisture content of flax noils slabs compared to materials made from a mixture of flax and polyester fibers, when using gyro-wind protection, the resulting structure of an insulation made of elementary fibers and liquid glass makes it possible to provide high heat transfer resistance values comparable to those of "Akoterm Flax" slabs.

\section{References}

1. V. Strikun, M. Strikun, A. Bayandin et al. Obtaining heat-insulating material from wood fiber based on bio-glue. Actual problems of forestry, 48, 86-87 (2017)

2. P. Ermolina, A. Mironov, A. Byvshev, Obtaining heat-insulating board material based on wood fiber. Actual problem of the forestry complex, 25, 186-189 (2010)

3. L. Zhuravleva, A. Zhuravleva, Soft fibreboard - thermal insulation material. KrasGAU Bulletin, 11, 181-184 (2010)

4. V. Beryukov, V. Danilov, N. Pashkov, Thermal insulation material RU 2149148 (2000)

5. S. Luchinin, V. Kozhukhov, Y. Alashkevich, Production of heat-insulating materials based on recycled cellulose fiber. IVUZ. Forest Journal, 6, 151-155 (2017)

6. A. Ermolina, P. Mironov, Obtaining and properties of thermal insulation material based on recycled fiber mass. IVUZ. Forest Journal, 4, 109-114 (2011)

7. S. Goreglyad, Environmentally friendly building materials. Construction Materials 4, 5-6 (1996)

8. G. Ivanov, New environmentally friendly thermal insulation material - ecowool. Construction Materials, 1, 21 (1995)

9. A. Bialosau, A. Bakatovich, F. Gaspar, Materiais compositos para isolamento termico de materias- primas naturais e aglutinantes minerais. Livro de Resumos 30 Congresso Luso - Brasileiro de Materiais de construcao sustentaveis. Coimbra, Portugal. 16-27 (2018)

10. A. Bakatovich, Microstructure as the main criterion for the use of sphagnum moss as a filler for an effective plate heat-insulating material. Polotsk State University Bulletin. Series F, 8, 42-46 (2017)

11.C. Becerra, J. Montory, A new biobased composite material using bark fibres eucalyptus. The $13^{\text {th }}$ pacific rim bio-based composites symposium «Bio-based composites for a sustainable future, 46-50 (2016)

12. E. YAkunina, Modern heat-insulating materials, as one of the trends in environmental construction. Synergy of Science, 24, 625-634 (2018)

13. T. Bogatova, A. Dvojcina, Advantages and features of safe natural heaters. Engineering systems and facilities, 3-4 (24-25), 14-19 (2016)

14. M. Rozyev, A. Bakatovich, Thermal insulation material, using waste cotton production as a placeholder. XI Junior Researchers, Conference. European \& national dimension in research. Architecture and civil engineering, 11, 64-66 (2019)

15. M. Rozyev, A. Bakatovich, Heat-insulating material based on cotton fiber waste. Polotsk State University Bulletin. Series F, 8, 29-33 (2019)

16. S. Hassan, A. Tesfamichael, M. Mohd, Nor Comparison study of thermal insulation characteristics from oil palm fibre. ICPER 2014 - 4 th International Conference on Production, Energy and Reliability, 13, 5 (2014) 
17. S. Romanovskiy, A. Bakatovich, Insulating material on the basis of bark fibre of the olive palm tree. IX junior researchers' conference «European and national dimension in research», 104-17 (2017)

18. D. Sovetnikov, D. Semashkina, D. Baranova, The optimal thickness of the outer wall insulation to create an energy efficient and environmentally friendly building in St. Petersburg. Construction of unique buildings and structures, 12 (51), 7-19 (2016).

19. Sound-absorbing heat-insulating plates. Technical conditions TU BY 391129716.0012015, 10 (2015)

20. Materials and products for construction thermal insulation. Test methods. GOST 1717794, 56 (1996)

21. Building materials and products. Methods for determining thermal conductivity in a stationary thermal regime. STB 1618-2006, 9 (2006)

22. Building thermal insulation materials. Method for determination of sorption moisture. STB EN 12088-2008, 9 (2009)

23. N. Davydenko, A. Bakatovich, Influence of the humidity index on the thermal conductivity coefficient of straw and wood-straw heat-insulating materials. Polotsk State University Bulletin, Series F, 8, 73-78 (2013)

24. Building thermal insulation materials. Method for determining vapor permeability. STB EN 12086-2007, 16 (2007) 